\title{
Measuring Thermal Stress of Dairy Cattle Based on Temperature Humidity Index (THI) in Tropical Climate
}

\author{
Sugiono ${ }^{1}$, Hardiningtyas Dewi ${ }^{1}$ and Soenoko Rudy ${ }^{2}$ \\ ${ }^{1}$ Industrial Engineering Department, Brawijaya University, Malang, East Java, Indonesia 65145 \\ ${ }^{2}$ Mechanical Engineering Department, Brawijaya University, Malang, East Java, Indonesia 65145
}

\begin{abstract}
Thermal comfort for workers is very important factor to increase their performance, as well as the comfort level of dairy cattle will influence in milk productivity. The purposes of the paper is to measure the level of heat stress and then use the information to design the dairy cattle house for increasing thermal comfort. The research is started with literature review of heat stress and early survey of environment condition e.g. temperature, wind speed and relative humidity. The next step is using the information to determine the temperature humidity index (THI) level for dairy cattle with maximum THI $=86$ and 84 (moderate stress). The 3D CAD model and Computational Fluid Dynamic (CFD) simulation are employed to looking for solution for reducing the discomfort thermal of dairy cattle. A scenario (fan) air conditioning to get better condition of thermal comfort have been successfully presented with final THI index $=76$ and 78 (mild stress). Finally, the paper shows how to reduce heat stress of cattle house by installation 3 exhaust fans in tropical climate.
\end{abstract}

\section{Introduction}

Dairy cattle in Indonesia is generally has less productivity of milk comparing to animal husbandry in sub-tropical countries like Australia, USA and Europe. It is not only about the quality of food, but also the level of cow comfort (environment condition) and design facility. The characteristic of tropical weather with higher relative humidity and warm temperature creates trend to increase heat stress. Moreover, currently dairy house design did not consider the needs of physic and psychology of dairy cattle. All the factors will affect the productivity of dairy cattle. Michel J. Brouk and friends on their research suggested that due to increasing the milk production, facility and climate effects should be a priority program in better dairy cow management [1].

There are a lot of researches about heat stress as one of comfort indicator for dairy cattle correlated with milk productivity. Animal science instructor Adrew P. Fidler and Karl Van Devender (2011) in his article stated that during the summer in Arkansas raises swordfish comfortable environmental conditions that can cause milk production of dairy cows has fallen dramatically with the average productivity is only $50 \%$ [2]. Even these conditions can disrupt the mating process a cow with a success rate only in the range of $10-20 \%$ only. J.W. West (2003) in his research entitled "Effect of Heat Stress on Production in Dairy Cattle" states that the temperature and high relative humidity will lead to high levels of heat stress in dairy cows [3]. High relative humidity values that cause cows difficult to release heat to the environment with regard to body temperature is much hotter than the environment, it will cause a disturbance in appetite/drinking, which in turn lowers milk production. Moreover, West (2003) noted that milk production declines as air temperature exceeds $24^{0} \mathrm{C}$ or falls below $12^{\circ} \mathrm{C}$. Further, Craig Thomas (2012) in his research on heat stress in cattle states that heat stress is a valuable strategy in the management of critical empowerment, especially dairy cows against temperature and relative humidity factor [4].

To cover the heat stress problem of dairy cattle, the physiological ergonomics knowledge is needed. Tropical climate with identical to hot and humid condition is important factor in analysing the heat stress level in order to increase cow comfort. Computer Aided Design (CAD) and Computational Fluid Dynamic (CFD) are beneficially help to looking for the best solution of thermal comfort for dairy cattle.

\section{Research theory}

Dairy cattle generally has a physical characteristic of mammary glands is larger than cow's beef cattle. Dairy cows is only benefitted for producing milk as maximum as possible. The best of dairy cattle is categorized as higher productivity, long-term productive and producing quality of milk. There are several factors that influence the total of milk production such us environment, species (breeds), individual factors, genetic, common factors, lactation, pregnancy, hormonal, lactation level, the persistence of production and body size of dairy cattle. 
The increasing of body weight of dairy cattle will add the production of milk proportionality.

The heat index was developed in 1978 by George Winterling and adopted by the USA National Weather Service a year later. It is derived from the work done by Robert G. Steadman [5]. As the wind chill index, heat index contains assumptions about the human body mass and height, clothing, amount of physical activity, blood type, exposure to sunlight and ultraviolet radiation, and wind speed [6]. Significant deviations from this will produce heat index values that do not accurately reflect the perceived temperature [7]. The thermal humidity index is an index that combines air temperature and relative humidity in an attempt to determine the level of heat that is felt by the animal body or generally known as the feeling temperature.

Table 1 shows temperature humidity index (THI) for dairy cattle. The THI with yellow explain that dairy cattle will feel start to stress. Medically, it characterized by respiratory exceed 60 beeps per minute (bpm). Based on previous research, the amount of milk in this area will be decreased at $1: 13 \mathrm{Kg}$ per day for each cow. The reproductive system is not functioning properly. But, the yellow region will not give negative impact brown colour is categorized as the region of mild to moderate stress. Medically characterized by respiratory exceed to 75 beeps per minute (bpm). The next is in the red region, it is moderate to severe stress situation of dairy cattle. Medically, it is characterized by respiratory exceed to 85 beeps per minute (bpm). The purple is in phase of heavy stress. Medically, it is indicated by respiratory exceed to 120 beeps per minute (bpm). Finally, the white areas explains that the dairy cattle cannot life in this area as temperature and relative humidity too high for animals

Table 1. Temperature humidity Index (THI) evaluation for dairy cattle in tropical situation [8].

\begin{tabular}{|c|c|c|c|c|c|c|c|c|}
\hline Temp. & \multicolumn{70}{|c|}{ Humidity (\%) } \\
\cline { 2 - 9 } $\mathbf{F}$ & $\mathbf{5 5}$ & $\mathbf{6 0}$ & $\mathbf{6 5}$ & $\mathbf{7 0}$ & $\mathbf{7 5}$ & $\mathbf{8 0}$ & $\mathbf{8 5}$ & $\mathbf{9 0}$ \\
\hline 72 & 69 & 69 & 69 & 70 & 70 & 70 & 71 & 71 \\
\hline 74 & 70 & 70 & 71 & 71 & 72 & 72 & 73 & 73 \\
\hline 76 & 72 & 72 & 73 & 73 & 74 & 74 & 75 & 75 \\
\hline 78 & 73 & 73 & 74 & 74 & 75 & 75 & 76 & 76 \\
\hline 80 & 75 & 76 & 76 & 77 & 78 & 78 & 79 & 79 \\
\hline 82 & 76 & 77 & 77 & 78 & 79 & 79 & 80 & 80 \\
\hline 84 & 78 & 78 & 79 & 80 & 80 & 81 & 82 & 83 \\
\hline 86 & 79 & 80 & 81 & 81 & 82 & 83 & 84 & 84 \\
\hline 88 & 81 & 81 & 82 & 83 & 84 & 85 & 86 & 86 \\
\hline 90 & 82 & 83 & 84 & 85 & 86 & 86 & 87 & 88 \\
\hline 92 & 84 & 85 & 85 & 86 & 87 & 88 & 89 & 90 \\
\hline 94 & 86 & 86 & 87 & 88 & 89 & 90 & 91 & 92 \\
\hline 96 & 87 & 88 & 89 & 90 & 91 & 92 & 93 & 94 \\
\hline 98 & 88 & 89 & 90 & 91 & 92 & 93 & 94 & 95 \\
\hline 100 & 90 & 91 & 92 & 93 & 94 & 95 & 96 & 98 \\
\hline 102 & 91 & 92 & 94 & 95 & 96 & 97 & 98 & 100 \\
\hline 104 & 93 & 94 & 95 & 96 & 98 & 99 & 100 & 101 \\
\hline 106 & 94 & 95 & 97 & 98 & 99 & 101 & 102 & 103 \\
\hline 108 & 96 & 97 & 98 & 100 & 101 & 103 & 104 & 105 \\
\hline 110 & 97 & 99 & 100 & 101 & 103 & 104 & 106 & 107 \\
\hline
\end{tabular}

Temperature humidity index for human is explained in Table 2. Similar with dairy cow, the human heat stress is divided into 6 regions for comfort area (green), caution area (yellow), extreme caution (brown), danger (red), extreme danger (purple) and deadly area (white). Purple area will impact heat syndrome on the human body, red area will impact stroke and light brown will impact heat cramps.

A study of the heat stress charts for cows and humans show that cows are much more sensitive to heat stress than people. People with environment temperature $26.67^{\circ} \mathrm{C}$ and relative humidity $40 \%$ are just start to feel heat stress, but the cow have been suffering for some time with THI $=73$ (light brown) or the dairy cattle get impact of moderate heat stress.

Computational Fluid Dynamics (CFD) is a calculation method with a control of dimensions, area and volume in special computer program as a simulation process [9]. The principle of the CFD is a chamber that contains the element of fluid which is presented into several parts, it is often called the cell and the process to build it is called meshing [10]. CFD is a calculation that specializes in fluid ranging from fluid flow, heat transfer and chemical reactions that occur in the fluid. According to the basic principles of fluid mechanics, the conservation of energy, momentum, mass, and species can be counted by the CFD simulation. As example, when a model will be analyzed by involving temperatures, it means that the model contents of the energy equation or the conservation of energy. Initialize the beginning of the equation is the boundary condition. Boundary condition is a condition in which the controls are defined as a calculation of the initial definition to be included into the calculation. In general, the CFD calculation process consists of three main parts: preprocessor, processor, post processor.

Table 2. Temperature humidity Index (THI) evaluation for human [8].

\begin{tabular}{|c|c|c|c|c|c|c|c|c|}
\hline Temp & \multicolumn{7}{|c|}{ Humidity (\%) } \\
\hline & $\mathbf{5 5}$ & $\mathbf{6 0}$ & $\mathbf{6 5}$ & $\mathbf{7 0}$ & $\mathbf{7 5}$ & $\mathbf{8 0}$ & $\mathbf{8 5}$ & $\mathbf{9 0}$ \\
\hline 72 & & & & & & & & \\
\hline 74 & & & & & & & & \\
\hline 76 & & & & & & & & \\
\hline 78 & & & & & & & & \\
\hline 80 & 81 & 82 & 82 & 83 & 84 & 84 & 85 & 86 \\
\hline 82 & 84 & 84 & 85 & 86 & 88 & 89 & 90 & 91 \\
\hline 84 & 86 & 88 & 89 & 90 & 92 & 94 & 96 & 98 \\
\hline 86 & 89 & 91 & 93 & 95 & 97 & 100 & 102 & 105 \\
\hline 88 & 93 & 95 & 98 & 100 & 103 & 106 & 110 & 113 \\
\hline 90 & 97 & 100 & 103 & 105 & 109 & 113 & 117 & 122 \\
\hline 92 & 101 & 105 & 108 & 112 & 116 & 121 & 126 & 131 \\
\hline 94 & 106 & 110 & 114 & 119 & 124 & 129 & 135 & \\
\hline 96 & 112 & 116 & 121 & 126 & 132 & & & \\
\hline 98 & 117 & 123 & 128 & 134 & & & & \\
\hline 100 & 124 & 129 & 136 & & & & & \\
\hline 102 & 130 & 137 & & & & & & \\
\hline 104 & 137 & & & & & & & \\
\hline 106 & & & & & & & & \\
\hline 108 & & & & & & & & \\
\hline 110 & & & & & & & & \\
\hline
\end{tabular}

The preprocessor is defined as activities to entry the input any information that are needed in simulation. The preprocessor data such as the information of environment condition (temperature, relative humidity, wind speed, wind direction), quality of meshing, defined axis, units, 
fluid, and goals of the simulation. The processor process is explained as the simulation process which is indicated by iteration process. The duration of simulation is depending on the complexity of the $3 \mathrm{D}$ model and the level quality of $3 \mathrm{D}$ meshing. The post processor process is used to show the simulation results as contour, 3D animation flow, and output of the goals.

\section{Research methodology}

According to the aim of the research as mentioned in introduction, the research will produce some recommendations of reducing THI for dairy cattle by modified air conditioning. The research is started with references of cow thermal comfort and correlated with Computational Fluid Dynamics (CFD). The research object location of dairy farmer is in Blitar district, East Java province, Indonesia. The collecting data of temperature, relative humidity, wind speed have been done in two periods for raining season (5 days) and dry season (5 days).To do collecting data some equipments are prepared such us: aerometer, thermometer, camera, stopwatch, etc.

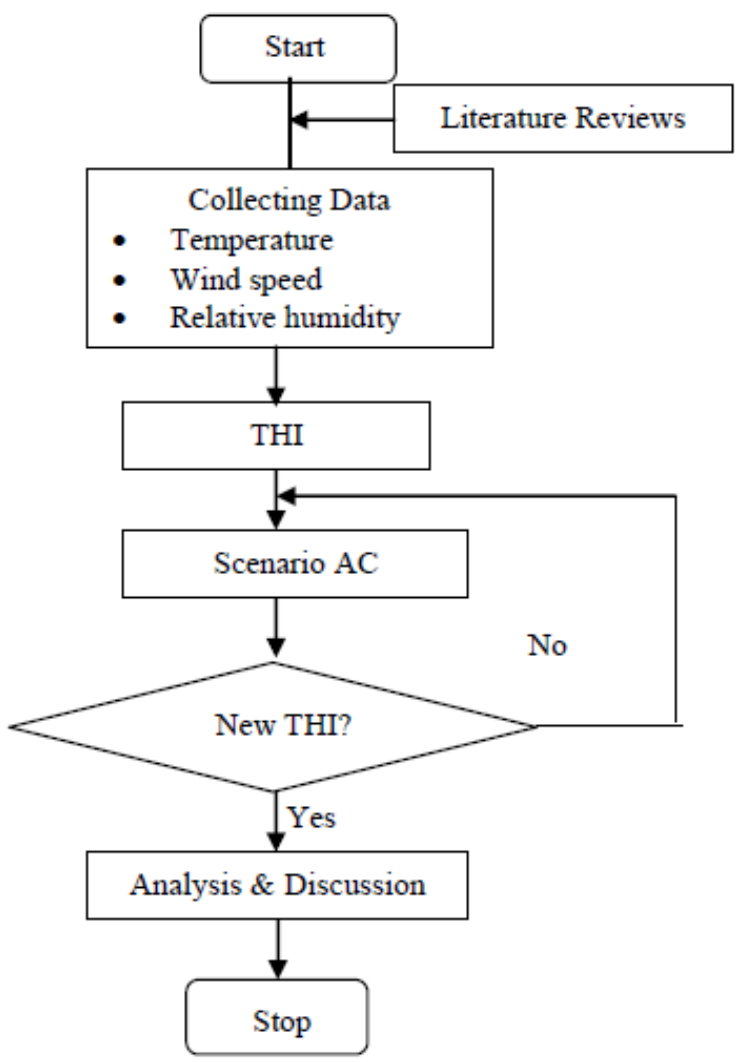

Figure 1. Flowchart of measuring and modifying THI for dairy cattle.

To control the steps of the research are logically right, flowchart of measuring THI and developing air conditioning $(\mathrm{AC})$ for dairy cattle house are presented as can be seen in figure 1 below. According to the graph, the next step after collecting environment data is measuring the THI existing. The THI is used as basic modification of design cow house for controlling the inner air quality (temperature and relative humidity).Analysis and discussion of reducing heat stress are presented in the last part of the research.

\section{Results and discussion}

Data of tropical environment condition (temperature, relative humidity, wind speed, wind direction) were collected during two seasons, the dry season and the rainy season. Generally, dry season in Indonesia occurs in May to October and wet season in November to June. During the dry season, Indonesia does not have rain. But sometimes, it rains with little rain-fall. The land is dry and it is hot during the season. Generally, there is no difference air quality (temperature and relative humidity) between inside and outside the dairy cattle house as low air circulation. The low air circulation is caused by bad layout and bad design dairy cattle house.

Table 3 shows some temperature averages data measurements which were collected in 3 difference time for fresh air (morning), hot temperature (day) and warm temperature (afternoon) in 5 days randomly during May to October. According to the table, the overall temperature average for dry season is $=29.6{ }^{\circ} \mathrm{C}$. The data of temperature is higher $1.3{ }^{\circ} \mathrm{C}$ than overall average in the Blitar district.

Table 3. Temperature data in dray season.

\begin{tabular}{|c|c|c|c|}
\hline \multirow{2}{*}{ Day } & \multicolumn{3}{|c|}{ Temperature $\left(\mathbf{C}^{\mathbf{C}}\right)-$ Dray Season } \\
\cline { 2 - 4 } & $\begin{array}{c}\text { Morning } \\
(\mathbf{0 7 . 0 0}-\mathbf{1 0 . 0 0 )}\end{array}$ & $\begin{array}{c}\text { Day } \\
(\mathbf{1 0 . 0 0}-\mathbf{1 5 . 0 0 )}\end{array}$ & $\begin{array}{c}\text { Afternoon } \\
(\mathbf{1 5 . 0 0}-\mathbf{1 7 . 0 0})\end{array}$ \\
\hline 1 & 27.3 & 30.9 & 27.6 \\
\hline 2 & 26.6 & 32.6 & 27.2 \\
\hline 3 & 27.8 & 31.2 & 27.5 \\
\hline 4 & 27.4 & 29.1 & 27.9 \\
\hline 5 & 26.4 & 32.7 & 27.7 \\
\hline
\end{tabular}

At the same time, the relative humidity $(\mathrm{RH})$ data were measured in 15 times with results as shown in table 4. The data of relative humidity is the amount of water vapour contained in the air around the dairy cattle house. The relative humidity in the research area tends to be higher in comparison with other areas in the surrounding districts. From the table, it can be shown that HR maximum is $89.7 \%$ and average $\mathrm{HR}$ is $87 \%$. The data of relative humidity is higher $6 \%$ than overall average in the Blitar district.

Table 4. Relative humidity data in dry season

\begin{tabular}{|c|c|c|c|}
\hline \multirow{2}{*}{ Day } & \multicolumn{3}{|c|}{ Relative Humidity (\%) -Dray Season } \\
\cline { 2 - 4 } & $\begin{array}{c}\text { Morning } \\
(\mathbf{0 7 . 0 0}-\mathbf{1 0 . 0 0 )}\end{array}$ & $\begin{array}{c}\text { Day } \\
(\mathbf{1 0 . 0 0}-\mathbf{1 5 . 0 0 )}\end{array}$ & $\begin{array}{c}\text { Afternoon } \\
\mathbf{( 1 5 . 0 0}-\mathbf{1 7 . 0 0 )}\end{array}$ \\
\hline 1 & 89.7 & 85.6 & 86.1 \\
\hline 2 & 87.5 & 87.3 & 85.4 \\
\hline 3 & 89.4 & 86.2 & 85.4 \\
\hline 4 & 87.9 & 87.4 & 85.6 \\
\hline 5 & 88.4 & 85.4 & 85.8 \\
\hline
\end{tabular}

Based on the explanation before, the temperature and relative humidity average are $29.6{ }^{\circ} \mathrm{C}$ and $87 \%$. By using Table 1 , the THI value for dry season is $\approx 84$ (red colour) or located in moderate - severe stress area (level 4 out of 
6 levels). It is characterized by respiratory exceed to 85 beeps per minute (bpm), feed intake will decrease and water consumption will increase, core body temperature will increase and milk production will decreased. Burgos Zimbelman and Collier (2011) [11] reported that the THI in red colour $(80-89)$ will reduce milk production around $=3.9 \mathrm{Kg} / \mathrm{cow} /$ day. The air quality should be maintained immediately to increase milk production and to eliminate the other impact of heat stress.

On the other hand, the air quality (temperature and relative humidity) in wet season are presented in Table 5 for temperature and Table 6 for relative humidity. According to the Table 5, the temperature data collected during the rainy season is at average of $=27^{\circ} \mathrm{C}$ with maximum data $=29.8^{\circ} \mathrm{C}$. The overall temperature average for dry season is $=29.6{ }^{\circ} \mathrm{C}$. The data of temperature is higher $2.1{ }^{\circ} \mathrm{C}$ than overall average in the Blitar district. Table 6 explains the HR maximum is $93.4 \%$ and average $\mathrm{HR}$ is $91 \%$. The data of relative humidity is higher $4 \%$ than overall average in the Blitar district.

Table 5. Temperature data in rainy season.

\begin{tabular}{|c|c|c|c|}
\hline \multirow{2}{*}{ Day } & \multicolumn{3}{|c|}{ Temperature $\left.\mathbf{(}^{\mathbf{0}} \mathbf{C}\right)-$ Raining Season } \\
\cline { 2 - 4 } & $\begin{array}{c}\text { Morning } \\
(\mathbf{0 7 . 0 0}-\mathbf{1 0 . 0 0 )}\end{array}$ & $\begin{array}{c}\text { Day } \\
(\mathbf{1 0 . 0 0}-\mathbf{1 5 . 0 0})\end{array}$ & $\begin{array}{c}\text { Afternoon } \\
(\mathbf{1 5 . 0 0}-\mathbf{1 7 . 0 0})\end{array}$ \\
\hline 1 & 25.9 & 29.8 & 25.3 \\
\hline 2 & 26.8 & 29.2 & 24.9 \\
\hline 3 & 25.5 & 28.1 & 24.6 \\
\hline 4 & 25.7 & 29.1 & 24.9 \\
\hline 5 & 26.7 & 27.4 & 24.7 \\
\hline
\end{tabular}

Table 6. Relative humidity data in rainy season.

\begin{tabular}{|c|c|c|c|}
\hline \multirow{2}{*}{ Day } & \multicolumn{3}{|c|}{ Relative Humidity (\%) -Raining Season } \\
\cline { 2 - 4 } & $\begin{array}{c}\text { Morning } \\
(\mathbf{0 7 . 0 0}-\mathbf{1 0 . 0 0 )}\end{array}$ & $\begin{array}{c}\text { Day } \\
(\mathbf{1 0 . 0 0}-\mathbf{1 5 . 0 0 )}\end{array}$ & $\begin{array}{c}\text { Afternoon } \\
\mathbf{( 1 5 . 0 0}-\mathbf{1 7 . 0 0 )}\end{array}$ \\
\hline 1 & 92.2 & 89.8 & 91.0 \\
\hline 2 & 91.5 & 89.2 & 90.6 \\
\hline 3 & 91.3 & 89.1 & 90.7 \\
\hline 4 & 93,4 & 89.7 & 90.6 \\
\hline 5 & 92.1 & 89.9 & 90.4 \\
\hline
\end{tabular}

Based on the average temperature $=27^{\circ} \mathrm{C}\left(80.60^{\circ} \mathrm{F}\right)$ and average relative humidity $=91 \%$ has the THI value $\approx$ 86 (red colour) or located in areas of moderate - severe stress area (level 4 out of 6 levels) with reducing of milk production around $=3.9 \mathrm{Kg} / \mathrm{cow} /$ day. In sort, the THI in wet season is higher than THI in dry season as the impact of $\mathrm{RH}$ in wet season is higher than dray season. It is clearly that THI in existing condition for both of dray season and wet season give higher alarm for famer to fix the problem sooner.

Workers get less heat stress than cow in both of wet and dry season. The table 2 can be used to examine the heat index (HI) level for human. The wet season with air temperature quality $=27{ }^{\circ} \mathrm{C}\left(80.60^{\circ} \mathrm{F}\right)$ and average relative humidity $=91 \%$ has the heat index $(\mathrm{HI})$ value $\approx$ 86 (yellow colour) or located in areas of light stress area (level 2 out of 6 levels). The dry season with air temperature quality $=29.6{ }^{0} \mathrm{C}\left(85.28^{\circ} \mathrm{F}\right)$ and average relative humidity $=87 \%$ has the heat index $(\mathrm{HI})$ value $\approx$ 102 (yellow colour) or located in areas of light stress area (level 2 out of 6 levels). All the seasons show there is no significant impact for human thermal comfort to disturb the human performance.

There are some strategies to increase milk production of dairy cattle as the impact of heat stress. Some recommendations to eliminate the effect of heat stress are: - $\quad$ Plant some trees surrounding the dairy cattle house to make natural shade. Trees are excellent source of shade and effective to block direct solar radiation. Moreover, trees photosynthesis can reduce heat energy and produce cold moisture. As consequence, cow thermal comfort will better than without tress near the cow house.

- The second recommendation of economically reducing heat stress is fan installation. Fan works to circulate fresh air (lower relative humidity and temperature) inside the cow house. In addition, fan can remove moisture which produced by cow body and others source get out the cow house. The fan specification and fan position determine the level of success for reducing heat stress. Figure 2a shows 3D CAD model for existing dairy cattle house design. The model is used to define the new scenario to reduce THI risk by installation low volume high speed (LVHS) - axial fan $050 \mathrm{~cm}$. The fan works to reduce temperature and relative humidity inside the cow house. It exploited the positive difference of air quality between inner and outer cattle house with average difference temperature $\Delta \mathrm{T}=1.3^{\circ} \mathrm{C}$ and relative humidity $(\mathrm{RH})=6 \%$ in dry season and $\Delta \mathrm{T}=2{ }^{\circ} \mathrm{C}$ and relative humidity $(\mathrm{RH})=4 \%$ in wet season. Figure $2 \mathrm{~b}$ explains the result of CFD simulation test for dairy cattle house with 3 fan in wet season. According to the test, the THI near cow is $\approx 76$ in light brown colour (mild stress) with average $\mathrm{T}=25.74^{\circ} \mathrm{C}$ and relative humidity $(\mathrm{RH})=$ $90.37 \%$. The new THI will reduce milk production to $\approx$ $2.7 \mathrm{Kg} / \mathrm{cow} /$ day. The same way, the CFD simulation test for dry conditions gives new THI index $\approx 78$ in light brown colour (mild stress) with average $\mathrm{T}=27.4^{\circ} \mathrm{C}$ $\left(81.32{ }^{\circ} \mathrm{F}\right)$ and relative humidity $(\mathrm{RH})=82.56 \%$.

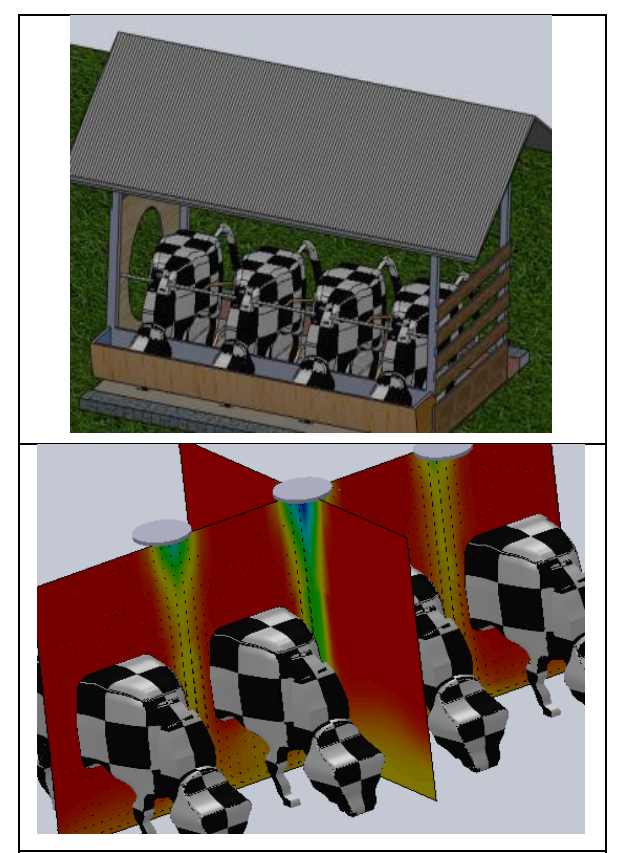

Figure 2. a. 3D design of existing dairy cattle house, b. CFD simulation for dairy cattle house using 3 fan. 
Beside installation fan and planting some trees, there are some methods to avoid heat stress for dairy cattle e.g. provide plenty of water for drink, sparkling water into cow body, increasing the roof venting, etc. The sparkling water is efficient method to reduce heat stress (increase milk production) but still need more investigation as requirement more electrical energy.

\section{Conclusions}

The research is successfully presented the measurement of temperature humidity index (THI) for dairy cattle in tropical climate, Indonesia. According to the THI calculation, the existing condition has high risk of thermal stress with class area in red colour (level 4). It will significantly reduce milk productivity around 3.9 $\mathrm{kg} /$ cow/day or decreasing $23 \%$ of standard milk production. One scenario to reduce heat stress is presented by benefited from the difference of $\mathrm{T}$ and $\mathrm{RH}$ between inner and outer cow house. It will reduce THI from 86 to 76 in wet season and from 84 to 78 in dry season. To reduce the heat stress, further action should be done in the future such as water sparkling treatment to reduce temperature and increasing the roof venting. Converting methane gas from cow waste to be electrical energy to generate fan or water sparkling is a big opportunity in concerning with green energy.

\section{Acknowledgment}

Thanks to the Ministry of National Education of the Republic of Indonesia for supporting this paper. The authors are also grateful to the laboratory of work design and ergonomics, Industrial Engineering Department, the
University of Brawijaya (UB), Malang Indonesia for their extraordinary courage.

\section{References}

1. B. J. Michael, S. F. Jhon, and H. P. Joseph, FCEDMI, Kansas State University Press, (2001).

2. Adrew P. Fidler, Karl VanDevender, Agriculture and Natural Resources Dept., (2016)

3. J.W. West, EHSPDC, Journal of dairy Science, 86, 2131-2144, (2003).

4. Craig Thomas, HSDC, Michigan State University Extension, (2012).

5. R. G. Steadman, TAS, Journal of Applied Meteorology, 18, 861-873, (1978).

6. Mikell P. Groover, WSM, Pearson Education, Inc., (2007).

7. Khalid Setaih at all, AOTC, $13^{\text {th }}$ CIBPSA, (2013).

8. Reynolds Jim, DFCC, Veterinary Medicine Teaching and Research Center, (2016)

9. Chung T.J., CFD, Cambridge University Press, (2011).

10. Doyle B. Joshua, GA, Auburn University Press, (2007).

11. Laurent Dussert, Aurelien Piron, HS, Lallemand Animal Nutrition, (2012)

12. V. Gantner et al, THI, Daily production of dairy cattle, 61, 56-63, (2011).

13. Ghavi Hossein-Zadeh, N., Mohit, A.and Azad, N., THI, Iranian Journal of Veterinary Research, Shiraz University, 14, 106-112, (2013).

14. Krawczel P., Grant Rick, CC, NMC Annual Meeting Proceedings, (2009).

15. Holter, J.B., J. W. West, M. 1. McGilliard and A.N. Pell..DCI. J. Dairy Sci., 79, 912-921, (1996). 